\title{
Medical Auditing of Outdoor Health Services of A Tertiary Care Hospital
}

\author{
Chinmoy Baidya ${ }^{1 *}$ \\ $M$ Jalal Uddin' \\ Saraj Uddin ${ }^{1}$ \\ Faheem Ul Hasan
}

1 Department of Community Medicine Chattogram Maa-O-Shishu Hospital Medical College Chattogram, Bangladesh.
*Correspondence to:

\section{Dr. Chinmoy Baidya}

Assistant Professor

Department of Community Medicine

Chattogram Maa-O-Shishu Hospital Medical College

Chattogram, Bangladesh.

Mobile: +8801818173444

Email: chinmoy.baidya@yahoo.com

Date of Submission : $\quad$ 05.09.2019

Date of Acceptance : $\quad 30.10 .2019$

www.banglajol.info/index.php/CMOSHMCJ

\begin{abstract}
Background: Medical auditing is a must to identify the short comings of health services provided by the health care providers and experienced by patients. The purpose of this study is to detect the supposing and opposing factors regarding outdoor health services to improve the quality of outdoor health services.
\end{abstract}

Materials and methods: This observational study was conducted among the patients visiting different outdoors of Chattogram Maa-O-Shishu Hospital from July to December 2017 by purposive sampling technique. Total 384 respondents were interviewed to fill out a pretested semi structured questionnaire. The data were collected and analyzed using the SPSS version 20.

Results: Among the patients, $86.72 \%$ resided within Chattogram City Corporation. Mean age was 24.14 ( \pm 13.18$)$ years, most (62.24\%) aged from 15 and 60 years and females (55.46\%) were predominant. Monthly income of the most (60.41\%) respondents was from 11000 to 20000 taka. Specialized service was the leading reason (40.62\%) followed by cost effectiveness (33.07\%) to select this hospital. Majority (47.14\%) came by themselves while $38.28 \%$ were referred by the relatives. Maximum (89.58\%) patients requiredless than 10 minutes time to collect ticket. Also most (92.19\%) required less than 10 minutes time to meet doctor. In addition, $60.68 \%$ of respondents availed lab facilities and $73.44 \%$ patients purchased medicine from hospital pharmacy. From non-buyers, unfamiliar location was the main reason in (23.18\%) most patients. Treatment cost was inexpensive for $95.31 \%$ respondents. Regarding behavior, 92.19\% were satisfied with doctors and 96.88\% were satisfied with staffs. Almost all (98.69\%) understood doctors' advice. However, the opposing factors stated by respondents were less waiting space $(5.47 \%)$, poor general cleanliness (2.605\%), long queue in pharmacy (2.605\%), bad toilet service (1.82\%), unclean water supply (1.30\%). Only 3 (0.78\%) experienced misbehavior. Majority (98.69\%) did not pay without receipt, but 1.04\% paid to security guard which is not acceptable.

Conclusion: By providing more emphasis on the deficiencies the service could be improved. Certain action plan with participation of all authorized people, it would be helpful to improve the quality of outdoor health services.

Key words: Medical auditing; Outdoor health service.

\section{INTRODUCTION}

Auditing is an important tool to understand the determinants in the variation of practice, and then to implement change which help to achieve a high quality of service, and thus contribute to the best possible outcome. Heath Insurance Organization (HIO) recognizes the medical audit as "a quality improvement process that seeks to improve patient care and outcomes through systematic review of care against explicit criteria and the implementation of change ${ }^{1}$." In medical practice, it is 
necessary to improve standard of care by maintaining best possible measure. By medical auditing the gap between service provided by the health care providers and experienced by patients could be reduced, thus quality of service will be improved. The term 'medical audit' tends to be applied to work done by physicians only ${ }^{2}$. Implementation of systematic quality assurance and medical audit programmes has become a prime issue in many hospitals in view of increasing standards of treatment and patient care. Doctors need to know how to use quality assurance and audit methods, and to see them as feasible and valuable for their work ${ }^{3}$. Chattogram Maa-OShishu Hospital is a rising organization in the health sector of Bangladesh hence it is important to identify the factors related to quality of outdoor health services.

\section{MATERIALS AND METHODS}

This was an observational study, done in the patient visiting different outdoors of Chattogram Maa-O-Shishu General Hospital from July 2017 to December 2017. Sample size was 384 at $95 \%$ CI, as expected proportion / prevalence of event was unknown. Purposive sampling technique was followed for data collection. Data were collected by the trained doctors by a pretested mixed type semi structured questionnaire. Patient receiving health care from outdoors were picked at exit point of hospital. In paediatric cases respective guardians were interviewed. They were interviewed carefully and all relevant documents were checked meticulously. Then, data were analyzed with the help of SPSS version 20 software.

\section{RESULTS}

Among the respondents, $86.72 \%$ resided within City Corporation while $10.6 \%$ were from outside of City Corporation. Mean age was $24.14( \pm 13.18)$ years, most (62.24\%) aged from 15 and 60 years. However, age of $36.46 \%$ of the patients was less than 15 years and only $1.30 \%$ aged more than 60 years. Females $(55.46 \%)$ were predominant than males (44.54\%) (Table I).

Specialization of service was the leading reason for most (40.62\%) of the cases followed by cost effectiveness (33.07\%), better facility (14.32\%) and choice of specific doctor (11.98\%) (Figure 1).

Among the care seeker, $47.14 \%$ came to the hospital by themselves but $38.28 \%$ were referred by relatives followed by $11.20 \%$ by friend, $2.60 \%$ by the doctors, $0.52 \%$ by hospital staffs and $0.26 \%$ by nurses. Less than 10 minutes time was required for most of the patients in collecting ticket $(89.58 \%)$ and to meet with the doctors $(92.19 \%)$. However, $7.81 \%$ needed 10 to 30 minutes for collecting ticket and $4.95 \%$ needed 10 to 30 minutes to meet with the doctors. Only $2.61 \%$ needed more than 30 minutes for collecting ticket and $2.86 \%$ needed more than 30 minutes to meet with the doctors. Majority (75.78\%) responded that total 30 to 60 minutes of time they needed to avail health care. Less than 30 minutes needed for $20.31 \%$ of the patients and more than 60 minutes needed for $3.91 \%$ patients.
However, behavior was satisfactory from $92.19 \%$ of doctors but $5.73 \%$ respondents were not satisfied. Only $1.30 \%$ respondents were highly satisfied and $0.78 \%$ did not answer. Satisfactory behavior from $96.88 \%$ of staff was found. Also, 05 (1.30\%) of the respondents gave opinion as highly satisfied and not satisfied. Only $0.52 \%$ did not answer (Table II).

Majority (60.68\%) availed lab session among the interviewed patients and rest (39.32\%) did not avail (Figure 2).

Most $(73.44 \%)$ of the respondents purchased medicine from hospital pharmacy but rest $26.56 \%$ did not (Figure 3).

Regarding the opposing factors 142 respondents answered. Of them, $23.18 \%$ expressed the location of pharmacy was unfamiliar followed by $5.47 \%$ stated about less waiting space, $2.695 \%$ told about poor general cleanliness, $2.605 \%$ told about long queue in pharmacy, $1.82 \%$ mentioned bad toilet service and $1.30 \%$ mentioned the water supply unclean. Rest (63.02\%) of the respondents had no comment in this regard (Table III).

Table I : Socio-demographic characteristics of the respondents

$\begin{array}{lll}\text { Characteristics } & \begin{array}{l}\text { Frequency } \\ (\mathbf{n}=384)\end{array} & \begin{array}{l}\text { Percentage } \\ (\%)\end{array}\end{array}$

Residence of patients

Within City corporation

86.72

Outside City corporation

51

Age of patients

$<15$ years

140

36.46

$15-60$ years

239

62.24

$>60$ years

5

1.9

Sex

$\begin{array}{lll}\text { Male } & 171 & 44.54 \\ \text { Female } & 213 & 55.46\end{array}$

Source: Study report 2017

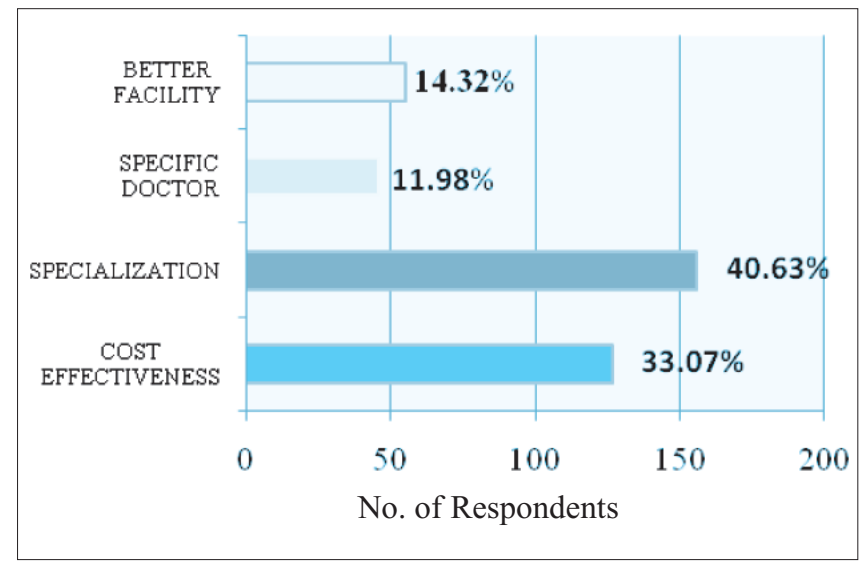

Figure 1 : Reason for selecting Chattogram Maa-O-Shishu Hospital 
Table II: Quality of service

\begin{tabular}{|c|c|c|}
\hline Characteristics & $\begin{array}{l}\text { Frequency } \\
\qquad(\mathrm{n}=384)\end{array}$ & $\begin{array}{r}\text { Percentage } \\
(\%)\end{array}$ \\
\hline \multicolumn{3}{|l|}{ Referring person } \\
\hline Self & 181 & 47.14 \\
\hline Relative & 147 & 38.28 \\
\hline Friend & 43 & 11.20 \\
\hline Doctor & 10 & 2.60 \\
\hline Nurse & 1 & 0.26 \\
\hline Hospital staff & 2 & 0.52 \\
\hline \multicolumn{3}{|c|}{ Time needed to collect ticket } \\
\hline$<10$ minutes & 344 & 89.58 \\
\hline $10-30$ minutes & 30 & 7.81 \\
\hline$>30$ minutes & 10 & 2.61 \\
\hline \multicolumn{3}{|c|}{ Time needed to meet with doctor } \\
\hline$<10$ minutes & 354 & 92.19 \\
\hline $10-30$ minutes & 19 & 4.95 \\
\hline$>30$ minutes & 11 & 2.86 \\
\hline \multicolumn{3}{|c|}{ Total time needed for availing health care } \\
\hline$<30$ minutes & 78 & 20.31 \\
\hline $30-60$ minutes & 291 & 75.78 \\
\hline$>60$ minutes & 15 & 3.91 \\
\hline \multicolumn{3}{|c|}{ Satisfaction with doctor's behavior } \\
\hline Highly satisfied & 5 & 1.30 \\
\hline Satisfied & 354 & 92.19 \\
\hline Not satisfied & 22 & 5.73 \\
\hline Not answered & 3 & 0.78 \\
\hline \multicolumn{3}{|c|}{ Satisfaction with staff behavior } \\
\hline Highly satisfied & 5 & 1.30 \\
\hline Satisfied & 372 & 96.88 \\
\hline Not satisfied & 5 & 1.30 \\
\hline Not answered & 2 & 0.52 \\
\hline
\end{tabular}

Source: Study report 2017

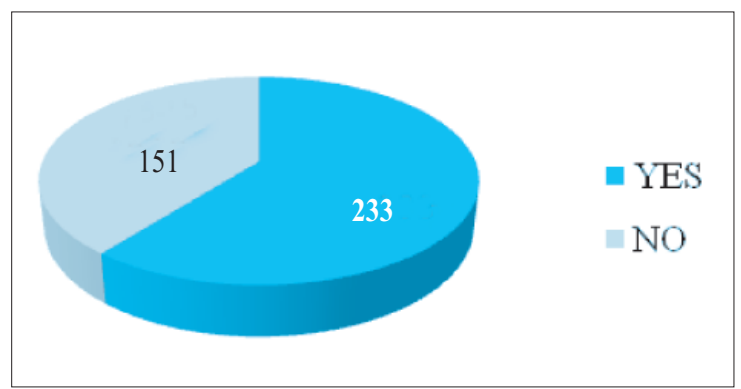

Figure 2 : Availing lab services

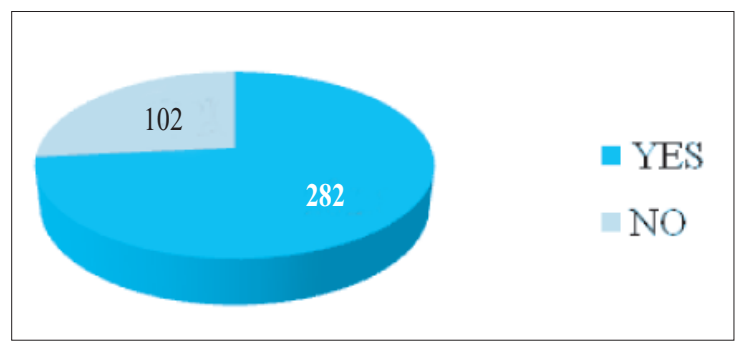

Figure 3 : Medicine purchased from hospital pharmacy
Table III : Opposing factors

\begin{tabular}{lcr} 
Characteristics & $\begin{array}{c}\text { Frequency } \\
(\mathbf{n}=\mathbf{3 8 4})\end{array}$ & $\begin{array}{r}\text { Percentage } \\
(\mathbf{\%})\end{array}$ \\
Unfamiliar location of pharmacy & 89 & 23.18 \\
Less waiting space & 21 & 5.47 \\
Poor general cleanliness & 10 & 2.605 \\
Long queue in pharmacy & 10 & 2.605 \\
Bad toilet service & 7 & 1.82 \\
Unclean water supply & 5 & 1.30 \\
No comment & 242 & 63.02 \\
\hline
\end{tabular}

Source: Study report 2017

\section{DISCUSSION}

- Mean service time was 50.69 minutes which need to be reduced.

- Most (60.41\%) had 11000 to 20000 taka monthly family income. Hence, reducing consultation fee may help this care seeker.

- Unfamiliar location of pharmacy contributes $23.18 \%$ people not to purchase medicine from hospital pharmacy.

- Though $60.67 \%$ of the patients availed lab service as per advice by physician but long waiting time, less waiting space and outdated lab service were unsatisfactory

- Although most were satisfied with the behavior of doctor and staff but need to mitigate the misbehavior in rest of the case.

- Payment without receipt is also found in a few cases $(1.30 \%)$ which are never acceptable

\section{CONCLUSION}

Overall services of Chattogram Maa-O-Shishu Hospital are satisfactory but there are scopes of further improvement even under short term plan. By providing more emphasis on the deficiencies the services could be improved. A broad based workshop on hospital service improvement is hereby advocated. Certain action plan with participation of all authorized people, it would be helpful to improve the quality of outdoor health services.

\section{ACKNOWLEDGEMENTS}

The authors would like to thank the participants and the hospital authority for their cooperation.

\section{DISCLOSURE}

All the authors declared no competing interest. 


\section{REFERENCES}

1. Thomas S, Rafeh N and Farag M. HIO Medical Audit Guidelines for Primary Health Care Clinics and Hospitals. Bethesda, MD: Health Systems 20/20 project.Abt Associates Inc. 2010;2.

2. MacDonald EB, Agius RM, McCloy ECet al.Quality and Audit in Occupational Health. London: Faculty of Occupational Medicine of the Royal College of Physicians of London. 1995.

3. Lawrence M. What is medical audit? In: Lawrence M, Schfield T, editors. Medical Audit in Primary Health Care. New York:Oxford University Press.1993. 